\title{
The distributions and correlates of serum albumin levels in institutionalised individuals with intellectual and/or motor disabilities
}

\author{
Hiroko Ohwada ${ }^{1}$ and Takeo Nakayama ${ }^{2}$ \\ ${ }^{1}$ Department of Food Sciences, Ibaraki Christian University, 6-11-1 Ohmika Hitachi, Ibaraki 319-1295, Japan \\ ${ }^{2}$ Department of Health Informatics, Kyoto University School of Public Health, Yoshida-Konoe-cho, Sakyo-ku, \\ Kyoto 606-8501, Japan
}

(Received 9 November 2007 - Revised 19 February 2008 - Accepted 5 March 2008 - First published online 11 April 2008)

The serum albumin level is a widely accepted indicator of nutritional status in healthy adults and elderly individuals. However, there are few data regarding the distribution and correlates of serum albumin levels in individuals with intellectual and/or motor disabilities. We conducted a crosssectional study at a public facility for individuals with intellectual and/or motor disabilities in Ibaraki prefecture, Japan. Health check-up data obtained in 2001 from 477 individuals with intellectual disability (286 males, average age 40.6 (SD 12.3) years; 191 females, average age 45.1 (SD 11.6) years) were retrospectively reviewed. With the exception of men with cerebral palsy, the serum albumin level was nearly normally distributed. The mean was 44 (SD 3.6) g/l for males and 44 (SD 3.6) g/l for females with intellectual disability, 43 (SD 3.2) g/l in males and 44 (SD 2.6) g/l for females with cerebral palsy, 41 (SD 2.7) g/l for males and 42 (SD 3.7) g/l for females with Down's syndrome, and 42 $(\mathrm{SD} 4.5) \mathrm{g} / \mathrm{l}$ for males and 41 (SD 3.2) $\mathrm{g} / \mathrm{l}$ for females with severe motor and intellectual disabilities. Only six of 474 individuals $(1.3 \%)$ had a serum albumin $\leq 35 \mathrm{~g} / \mathrm{l}$. Low serum albumin was related to age, use of anticonvulsants and/or major tranquilisers, use of other medications, high C-reactive protein (CRP), high zinc sulfate turbidity test (ZTT), low serum $\mathrm{Hb}$ and low serum $\mathrm{Fe}$ among men; among women, high CRP and high ZTT were related to low serum albumin. The present study found an unexpectedly low incidence of low serum albumin among institutionalised individuals with intellectual and/or motor disabilities. Low serum albumin was associated with age, medications and inflammation in men, as well as inflammation in women.

Serum albumin: Intellectual disability: Motor disability

The 1992 American Association on Mental Retardation's definition and classification of mental retardation differs from the previous classification system in that: (a) a single diagnostic code of mental retardation is used if the individual meets the three criteria of age of onset (18 years or under), significantly sub-average abilities in intellectual functioning, and related limitations in two or more adaptive skills areas; (b) the individual's strengths and weaknesses are described in reference to four dimensions - (i) intellectual functioning and adaptive skills, (ii) psychological and emotional wellbeing, (iii) health, physical wellbeing and aetiology, and (iv) life activity environments; (c) a profile of required support is developed across the four dimensions ${ }^{(1)}$.

In Japan, methods of appropriate nutritional management for disabled individuals have attracted increasing attention following the implementation of the Handicapped Individual Independence Support Law in April 2006. However, epidemiological research dealing with the health and diseases of individuals with intellectual and/or motor disabilities lags far behind that dealing with the health and diseases of individuals with no intellectual and/or motor disabilities. Among apparently healthy individuals, particularly elderly individuals, low serum albumin is used as an indicator of poor nutritional status ${ }^{(2-7)}$. In Japan, the following indicators are used to assess the malnutrition risk level among the elderly: low risk, $\geq 36 \mathrm{~g} / \mathrm{l}$; medium risk, $30-35 \mathrm{~g} / \mathrm{l}$; high risk, $<30 \mathrm{~g} / \mathrm{l}^{(8)}$. However, no epidemiological studies have been conducted that deal with the distribution and correlates of serum albumin levels. We conducted a cross-sectional study examining the distributions and correlates of serum albumin levels among institutionalised individuals with intellectual and/or motor disabilities based on blood profile tests conducted periodically at their facility. A previous report found that the zinc sulfate turbidity test (ZTT), which reflected inflammation, was a cause of reduced $\mathrm{Hb}$ levels, which is an indicator of nutritional status $^{(9)}$. Therefore, correlations between inflammatory factors and the serum albumin level, which is another important indicator of nutritional status, were primarily studied.

\section{Methods}

The present study analysed the data of 315 individuals with intellectual disability, ninety with cerebral palsy, thirty-three with Down's syndrome, and thirty-nine with severe motor 
and intellectual disabilities. The subjects were a population of 477 individuals with intellectual disability (286 males, average age 40.6 (SD 12.3) years; 191 females, average age 45.1 (SD 11.6) years) institutionalised at a public facility located in Ibaraki prefecture $(109 \mathrm{~km}$ north of Tokyo, with a population of approximately 3 million), Japan. In 2001, 12600 individuals in Ibaraki prefecture were recognised as being intellectually disabled. This public facility houses the more severely disabled individuals; over $95 \%$ of the residents were judged as having a severe intellectual disability.

In Japan, periodic health check-ups are provided for individuals in order to prevent lifestyle-related diseases, including circulatory diseases. The tests that are done have been previously recommended as screening tests for various diseases. The present study retrospectively analysed the existing health check-up data for each resident. The following information was collected during periodic health check-ups done in 2001: blood biochemistry examinations, blood pressure, main disability, main diagnosis, intelligence quotient, and information regarding medications. The modified Binet test for Japanese was used to calculate the intelligence quotient on admission.

Correlates of serum albumin levels were assessed on multiple regression analysis using the serum albumin level as a dependent variable, and age, BMI, anticonvulsants and/or major tranquilisers, minor tranquilisers, other medications (i.e. gastrointestinal drugs, drugs for the common cold, cardiovascular medications), and serum $\mathrm{Hb}$, as well as C-reactive protein (CRP) and ZTT as indices of inflammation. The ZTT is a turbidity test in which reagents are added to the serum samples; the ZTT findings reflect the levels of $\gamma$-globulins, particularly IgG. Multivariate analysis was conducted using only three categories of individuals with intellectual disability.
Since the characteristics of individuals with severe motor and intellectual disabilities were very different from individuals in the other categories, individuals with intellectual disability, cerebral palsy and Down's syndrome were combined into one category.

All statistical analyses were performed using SPSS $^{\circledR}$ version 15.0 statistical software (SPSS Inc., Chicago, IL, USA). Significance was established at the $P=0.05$ level. The research protocol was approved by the Institutional Review Board at Miyagi Gakuin Women's University, with which the first author $(\mathrm{H}$. O.) was affiliated at the time the present study was conducted.

\section{Results}

Tables 1 and 2 show the characteristics of the 315 institutionalised individuals with intellectual disability, the ninety with cerebral palsy, the thirty-three with Down's syndrome and the thirty-nine with severe motor and intellectual disabilities. The average BMI was $21.5 \mathrm{~kg} / \mathrm{m}^{2}$ for male subjects and $22.0 \mathrm{~kg} / \mathrm{m}^{2}$ for female subjects with intellectual disability, $20.7 \mathrm{~kg} / \mathrm{m}^{2}$ for male subjects and $21.6 \mathrm{~kg} / \mathrm{m}^{2}$ for female subjects with cerebral palsy, $22.2 \mathrm{~kg} / \mathrm{m}^{2}$ for male subjects and $24.0 \mathrm{~kg} / \mathrm{m}^{2}$ for female subjects with Down's syndrome, and $14.3 \mathrm{~kg} / \mathrm{m}^{2}$ for male subjects and $15.1 \mathrm{~kg} / \mathrm{m}^{2}$ for female subjects with severe motor and intellectual disabilities. With respect to the blood profiles, the average erythrocyte count, leucocyte count, serum Fe level, total protein level, serum albumin level, total cholesterol level, and HDL-cholesterol level were all within their respective normal ranges. The average $\mathrm{Hb}$ level for males with severe motor and intellectual disabilities was $130 \mathrm{~g} / \mathrm{l}$, which was lower than the normal range $(135-176 \mathrm{~g} / \mathrm{l})$. In contrast, the average $\mathrm{Hb}$ levels for

Table 1. Characteristics of institutionalised individuals with intellectual disability in lbaraki prefecture, Japan (Mean values and standard deviations)

\begin{tabular}{|c|c|c|c|c|c|c|c|c|}
\hline & \multicolumn{4}{|c|}{ Individuals with intellectual disability ( $n$ 315) } & \multicolumn{4}{|c|}{ Individuals with cerebral palsy ( $n 90$ ) } \\
\hline & \multicolumn{2}{|c|}{ Male ( $n$ 197) } & \multicolumn{2}{|c|}{ Female ( $n$ 118) } & \multicolumn{2}{|c|}{ Male $(n 48)$} & \multicolumn{2}{|c|}{ Female ( $n$ 42) } \\
\hline Age (years) & $40 \cdot 3$ & $14 \cdot 0$ & $47 \cdot 1$ & 11.4 & $42 \cdot 1$ & $10 \cdot 7$ & $43 \cdot 0$ & $11 \cdot 8$ \\
\hline Intelligence quotient ${ }^{\star} \dagger$ & $29 \cdot 0$ & $10 \cdot 1$ & $28 \cdot 8$ & $10 \cdot 8$ & $29 \cdot 7$ & $11 \cdot 7$ & $25 \cdot 1$ & $16 \cdot 8$ \\
\hline Height $(\mathrm{cm})$ & $158 \cdot 8$ & $9 \cdot 6$ & $146 \cdot 4$ & $8 \cdot 0$ & $154 \cdot 4$ & $9 \cdot 2$ & $143 \cdot 1$ & $7 \cdot 5$ \\
\hline $\operatorname{BMI}\left(\mathrm{kg} / \mathrm{m}^{2}\right)$ & 21.5 & 3.6 & $22 \cdot 0$ & 3.8 & $20 \cdot 7$ & 3.0 & 21.6 & $3 \cdot 7$ \\
\hline Erythrocytes $\left(\times 10^{6} / \mu \mathrm{l}\right)$ & 4.5 & 0.5 & $4 \cdot 1$ & 0.3 & 4.5 & 0.5 & $4 \cdot 1$ & 0.3 \\
\hline Leucocytes $\left(\times 10^{3} / \mu \mathrm{l}\right)$ & $5 \cdot 9$ & 1.8 & $5 \cdot 6$ & 1.7 & $5 \cdot 7$ & $1 \cdot 8$ & $5 \cdot 2$ & 1.4 \\
\hline $\mathrm{Hb}(\mathrm{g} / \mathrm{l})$ & 137 & 12 & 126 & 8 & 137 & 13 & 125 & 8 \\
\hline $\mathrm{Fe}(\mu \mathrm{g} / \mathrm{l})$ & 990 & 396 & 1038 & 308 & 1034 & 446 & 991 & 365 \\
\hline Total protein $(\mathrm{g} / \mathrm{l})$ & 72 & 6 & 71 & 7 & 73 & 4 & 72 & 5 \\
\hline Albumin $(g / l)$ & 44 & 4 & 43 & 5 & 43 & 3 & 44 & 3 \\
\hline Total cholesterol (mg/l) & 1647 & 335 & 1916 & 394 & 1688 & 302 & 1854 & 360 \\
\hline C-reactive protein (mg/l) & 6 & 16 & 3 & 11 & 8 & 13 & 11 & 2 \\
\hline \multicolumn{9}{|c|}{ Cases using certain medications } \\
\hline$n$ & \multicolumn{2}{|c|}{143} & \multicolumn{2}{|c|}{75} & \multicolumn{2}{|c|}{38} & \multicolumn{2}{|c|}{30} \\
\hline$\%$ & \multicolumn{2}{|c|}{$72 \cdot 6$} & \multicolumn{2}{|c|}{63.6} & \multicolumn{2}{|c|}{$79 \cdot 2$} & \multicolumn{2}{|c|}{$71 \cdot 4$} \\
\hline
\end{tabular}

ZTT, zinc sulfate turbidity test.

${ }^{\star}$ For intelligence quotient, 107 male subjects and eighty-one female subjects with intellectual disability.

†For intelligence quotient, twenty-four male subjects and twenty-two female subjects with cerebral palsy. 
Table 2. Characteristics of institutionalised individuals with intellectual disability in Ibaraki prefecture, Japan (Mean values and standard deviations)

\begin{tabular}{|c|c|c|c|c|c|c|c|c|}
\hline & \multicolumn{4}{|c|}{$\begin{array}{l}\text { Individuals with Down's } \\
\text { syndrome ( } n \text { 33) }\end{array}$} & \multicolumn{4}{|c|}{$\begin{array}{l}\text { Individuals with severe motor and } \\
\text { intellectual disabilities }(n 39)\end{array}$} \\
\hline & \multicolumn{2}{|c|}{ Male $(n 20)$} & \multicolumn{2}{|c|}{ Female $(n 13)$} & \multicolumn{2}{|c|}{ Male ( $n$ 21) } & \multicolumn{2}{|c|}{ Female $(n 18)$} \\
\hline & Mean & SD & Mean & SD & Mean & SD & Mean & SD \\
\hline Age (years) & $42 \cdot 1$ & 9.5 & 47.5 & $6 \cdot 1$ & 38.5 & $10 \cdot 6$ & $35 \cdot 2$ & $9 \cdot 9$ \\
\hline Intelligence quotient ${ }^{*} \dagger$ & $23 \cdot 3$ & $6 \cdot 3$ & 14.4 & $12 \cdot 8$ & $27 \cdot 6$ & 14.6 & $29 \cdot 6$ & 11.3 \\
\hline Height $(\mathrm{cm})$ & $146 \cdot 3$ & $6 \cdot 1$ & 137.4 & 5.5 & 151.4 & 13.9 & $145 \cdot 9$ & 8.4 \\
\hline Weight (kg) & $47 \cdot 7$ & $9 \cdot 3$ & $45 \cdot 1$ & 7.5 & $33 \cdot 2$ & $7 \cdot 2$ & $32 \cdot 1$ & 7.5 \\
\hline $\mathrm{BMI}\left(\mathrm{kg} / \mathrm{m}^{2}\right)$ & $22 \cdot 2$ & 3.5 & $24 \cdot 0$ & 4.3 & $14 \cdot 3$ & $2 \cdot 4$ & $15 \cdot 1$ & $3 \cdot 2$ \\
\hline Erythrocytes $\left(\times 10^{6} / \mu \mathrm{l}\right)$ & $6 \cdot 7$ & $10 \cdot 2$ & 4.2 & 0.3 & $4 \cdot 2$ & 0.4 & $4 \cdot 1$ & 0.4 \\
\hline Leucocytes $\left(\times 10^{3} / \mu \mathrm{l}\right)$ & $6 \cdot 2$ & $2 \cdot 6$ & $4 \cdot 8$ & $1 \cdot 3$ & 5.4 & $1 \cdot 7$ & $6 \cdot 0$ & $2 \cdot 4$ \\
\hline $\mathrm{Hb}(\mathrm{g} / \mathrm{l})$ & 143 & 11 & 135 & 7 & 130 & 13 & 125 & 14 \\
\hline $\mathrm{Fe}(\mu \mathrm{g} / \mathrm{l})$ & 899 & 259 & 1010 & 299 & 901 & 292 & 1051 & 438 \\
\hline Total protein (g/l) & 74 & 5 & 75 & 3 & 72 & 6 & 74 & 5 \\
\hline Albumin $(\mathrm{g} / \mathrm{l})$ & 41 & 3 & 42 & 4 & 42 & 4 & 41 & 3 \\
\hline Total cholesterol (mg/l) & 1762 & 197 & 2018 & 348 & 1813 & 325 & 1884 & 350 \\
\hline HDL-cholesterol (mg/l) & 497 & 110 & 629 & 145 & 554 & 162 & 531 & 130 \\
\hline ZTT (units) & 15.5 & 4.4 & 15.5 & $5 \cdot 0$ & 9.8 & $4 \cdot 2$ & $12 \cdot 0$ & $5 \cdot 2$ \\
\hline C-reactive protein $(\mathrm{mg} / \mathrm{l})$ & 6 & 9 & 5 & 10 & 6 & 20 & 7 & 20 \\
\hline \multicolumn{9}{|c|}{ Cases using specific medications } \\
\hline$n$ & \multirow{2}{*}{\multicolumn{2}{|c|}{$\begin{array}{c}11 \\
55.0\end{array}$}} & \multirow{2}{*}{\multicolumn{2}{|c|}{$\begin{array}{c}5 \\
\end{array}$}} & \multirow{2}{*}{\multicolumn{2}{|c|}{-}} & \multirow{2}{*}{\multicolumn{2}{|c|}{-}} \\
\hline$\%$ & & & & & & & & \\
\hline
\end{tabular}

ZTT, zinc sulfate turbidity test.

${ }^{*}$ For intelligence quotient, thirteen male subjects and eleven female subjects with Down's syndrome.

†For intelligence quotient, eleven male subjects and five female subjects with severe motor and intellectual disabilities.

individuals in the other categories were all within normal ranges. The average ZTT level for individuals with Down's syndrome (male and female) was 15.5 units, which was slightly higher than the normal range (4-12 units). The average CRP for the four categories of individuals, which ranged from 6 to $11 \mathrm{mg} / \mathrm{l}$, was higher than the normal range $(0-3 \cdot 0 \mathrm{mg} / \mathrm{l})$.

Fig. 1 shows the serum albumin level distribution among the 474 institutionalised individuals with intellectual and/or motor disabilities. Only six of 474 individuals $(1.3 \%)$ had a low serum albumin level (serum albumin $\leq 35 \mathrm{~g} / \mathrm{l}$ ), including two men and two women with intellectual disability and one man and one woman with severe motor and intellectual disabilities. None of the individuals with cerebral palsy or Down's syndrome had a low serum albumin level.

Fig. 2 shows the relationship between BMI and serum albumin. In all groups with a BMI from $\leq 15 \cdot 0 \mathrm{~kg} / \mathrm{m}^{2}$ to a BMI of $\geq 27 \cdot 1 \mathrm{~kg} / \mathrm{m}^{2}$, the mean serum albumin levels were between 43 and $44 \mathrm{~g} / 1$ among men and between 41 and $44 \mathrm{~g} / 1$ among women, indicating that there were no cases of hypoalbuminaemia.

Table 3 shows the predictors of the serum albumin level among the 433 institutionalised individuals with intellectual and/or motor disabilities. The following factors were identified as being correlated with a low serum albumin level: age, use of anticonvulsants and/or major tranquilisers, use of other medications, high CRP, high ZTT, low serum $\mathrm{Hb}$ and low serum $\mathrm{Fe}$ among men, as well as high CRP and ZTT among women.

\section{Discussion}

To date, no large-scale epidemiological studies dealing with individuals with intellectual and/or motor disabilities residing in the same environment at a single facility have been conducted. The present findings are significant in terms of broadening our view of the health status of individuals with intellectual and/or motor disabilities.

A low serum albumin level is widely used as an indicator of poor nutritional status ${ }^{(2-7)}$. Physiologically, serum albumin levels of 35 and $\leq 28 \mathrm{~g} / \mathrm{l}$ have been reported to result in visceral protein depletion and oedema, respectively ${ }^{(2)}$. Epidemiologically, a serum albumin level of $\leq 35 \mathrm{~g} / \mathrm{l}$ has been shown to be an independent risk factor for total mortality (all-cause mortality $)^{(3-5)}$. Clinically, a serum albumin level of $\leq 30 \mathrm{~g} / \mathrm{l}$ has been associated with a 2- to 3-fold increase in the incidence of post-operative complications ${ }^{(6)}$, as well as a $3 \cdot 5$-fold increase in mortality at 12 weeks post-operatively $(38.1 \%)$, while a serum albumin level of $\leq 35 \mathrm{~g} / \mathrm{l}$ has been reported to result in a 1.9-fold increase in mortality at 2 years post-operatively $(63.2 \%)^{(7)}$. In addition, a serum albumin level of $\leq 35 \mathrm{~g} / \mathrm{l}$ has been reported to represent a medium risk for protein-energy malnutrition in acute and long-term care facilities in the USA. In Japan, a serum albumin level of $\leq 35 \mathrm{~g} / \mathrm{l}$ is noted in approximately $40 \%$ of elderly individuals admitted to medical facilities and in approximately $30 \%$ of elderly individuals requiring homecare, such as nutrition and diet consultations ${ }^{(10)}$. Although we initially thought that a high proportion of institutionalised individuals with disabilities would have a serum albumin level of $\leq 35 \mathrm{~g} / \mathrm{l}$, in fact an unexpectedly small number of such cases was found. The primary reason for this result may be that the individuals institutionalised at the present facility regularly received meals of adequate quality and quantity and their intake was monitored ${ }^{(11)}$. The 2005 version of the Japanese dietary reference intakes expresses protein intake in terms of the estimated average requirement, RDA, and target intake 
(a)

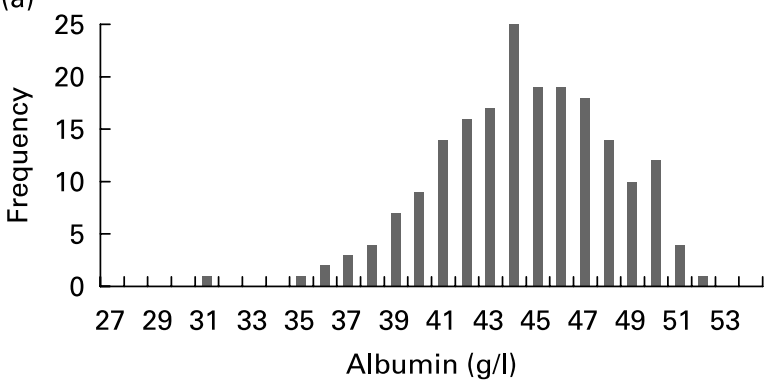

(c)

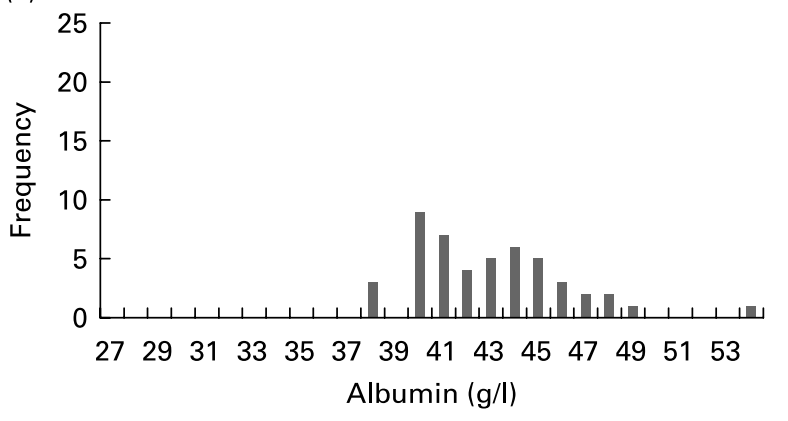

(e)

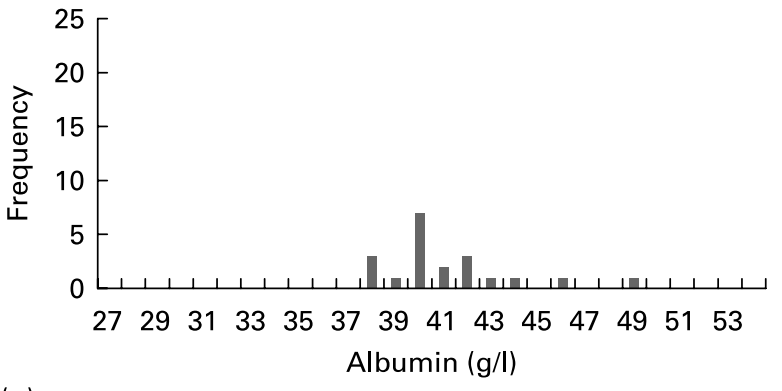

(g)

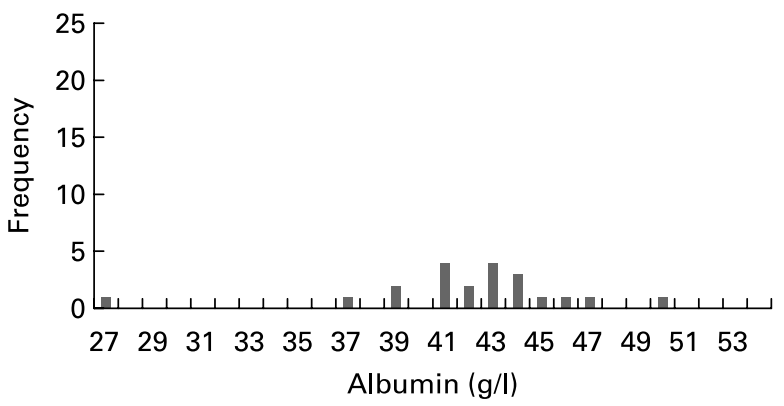

(b)

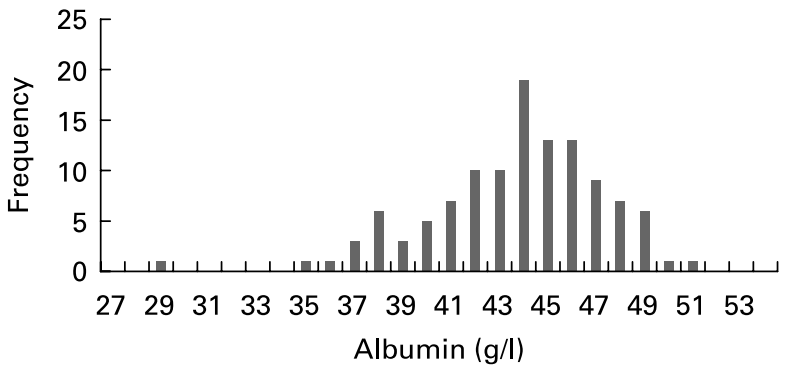

(d)

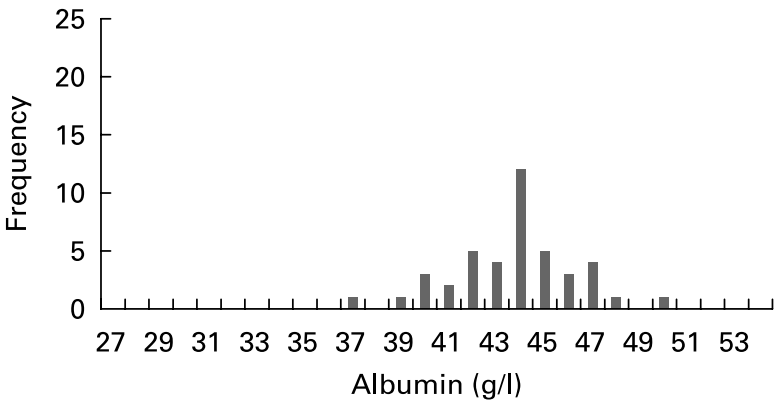

(f)

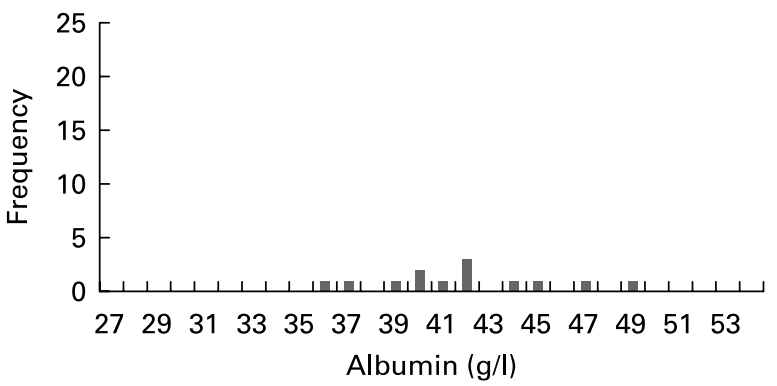

(h)

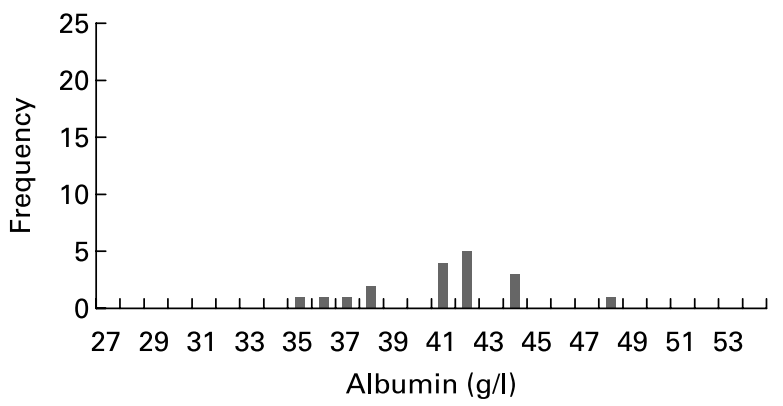

Fig. 1. The serum albumin distributions among 474 institutionalised indiviudals with intellectual and/or motor disabilities in Ibaraki prefecture, Japan. (a) Men with intellectual disability ( $n$ 196): mean 44 (SD 3.6), range 31-52 g/l, missing data for one man. (b) Women with intellectual disability ( $n$ 116): mean 44 (SD 3.6), range 29-51 g/l, missing data for two women. (c) Men with cerebral palsy ( $n$ 48): mean 43 (sD 3.2), range 38-54 g/l. (d) Women with cerebral palsy ( $n 42)$ : mean 44 (SD 2.6), range 37-50 g/l. (e) Men with Down's syndrome ( $n$ 20): mean 41 (sD 2.7), range 38-49 g/l. (f) Women with Down's syndrome ( $n$ 13): mean 42 (sD 3.7), range 36-49 g/l. (g) Men with severe motor and intellectual disabilities ( $n$ 21): mean 42 (sD 4.5), range 27-50 g/l. (h) Women with severe motor and intellectual disabilities ( $n$ 18): mean 41 (SD 3.2), range $35-48 \mathrm{~g} / \mathrm{l}$.

(\% energy, $<20 \%$ ). Since the present facility provided meals according to the target intake, which corresponds to the highest level of protein intake, the residents of this facility appear to have maintained adequate protein levels. Second, albumin is synthesised in the liver. Since in the present study the aspartate transaminase and alanine transaminase levels of all individuals with a low serum albumin were within the normal ranges, their liver function and synthetic capacity were relatively maintained.
Cross-sectional investigation of the correlates of a low serum albumin level identified the following correlates: age, use of anticonvulsants and/or major tranquilisers, use of other medications, high CRP, high ZTT, low serum $\mathrm{Hb}$ and low serum $\mathrm{Fe}$ among males, as well as high CRP and high ZTT among females. The present findings suggest that males taking medications have an increased risk of a low serum albumin level, though no such relationship was observed in females. The present data regarding medications 

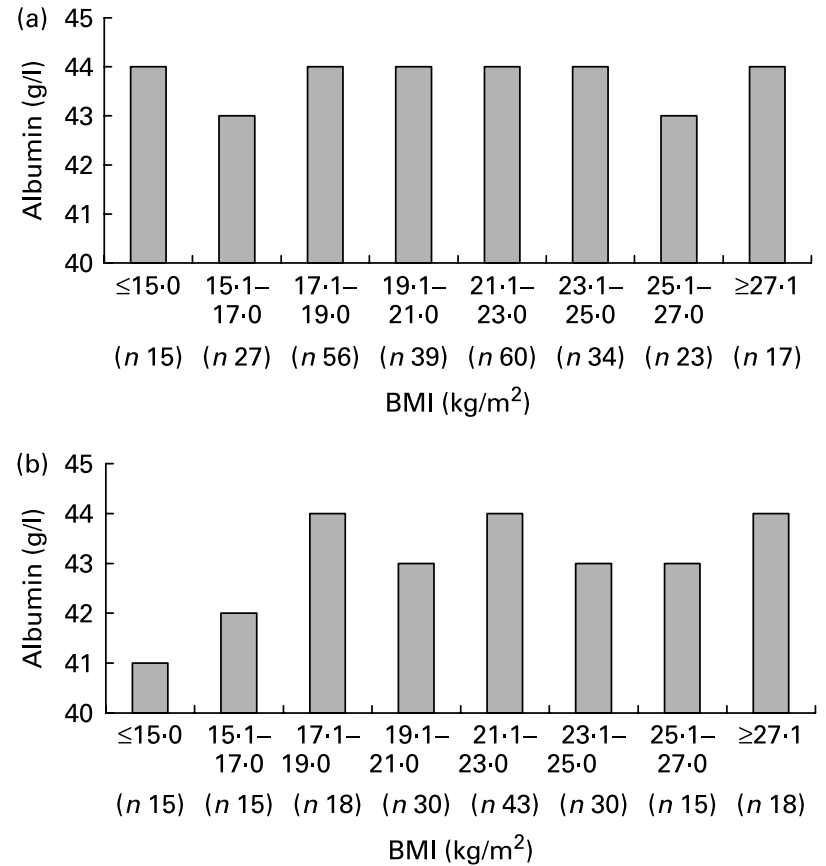

Fig. 2. Relationship between BMI and albumin among 455 institutionalised individuals with intellectual and/or motor disabilities in lbaraki prefecture, Japan: (a) males ( $n$ 271); (b) females ( $n$ 184). Data were missing for fifteen males and seven females.

were obtained through a review of existing medical records and only took into account the use of the medications at the time of the survey. A detailed analysis of the medications' duration of use and dose could not be performed. The relationship that was observed only in males may have been attributable to higher drug doses in males than in females.
Since a high ZTT is thought to reflect high IgG levels, a high ZTT level may be related to chronic inflammation. While chronic and acute inflammation may conceivably reduce the serum albumin level, the focus of this relationship must be clarified. As described in our previous report, though no particular factors were identified on the general systematic evaluation done as part of the periodic health check-ups, the presence of periodontal disease and caries resulting from poor oral hygiene may be related to chronic inflammation ${ }^{(8)}$. Disabled individuals may have difficulty maintaining oral hygiene without assistance. The authors plan to assess data obtained from dental health check-ups in a subsequent study.

BMI is an indicator of nutritional status, and may thus be related to the serum albumin level ${ }^{(12)}$. In the present study, however, there was no relationship between BMI and the serum albumin level. In addition, with respect to the relationship between BMI and the serum albumin level, the average serum albumin among individuals with a BMI of $\leq 15.0 \mathrm{~kg} / \mathrm{m}^{2}$ was $44 \mathrm{~g} / 1$ for males $(n 15)$ and $41 \mathrm{~g} / \mathrm{l}$ for females ( $n$ 15); both of these were within the normal range. This finding may be due to the fact that the present facility ensured that its residents maintained an adequate protein intake; in addition, even individuals with a low BMI maintained reasonable liver function, as indicated by their normal aspartate transaminase and alanine transaminase levels. Third, in a previous study that compared the body compositions of individuals with intellectual disability and healthy individuals, individuals with intellectual disability were found to have a higher body fat percentage and a lower lean body mass than healthy individuals with the same $\mathrm{BMI}^{(11)}$. Therefore, differences in BMI among disabled individuals may primarily reflect the amount of body fat that is present.

The present study found an unexpectedly low incidence of low serum albumin levels among institutionalised individuals with intellectual and/or motor disabilities. In addition, a low

Table 3. Correlates of low serum albumin in 433 institutionalized individuals with intellectual and/or motor disabilities in Ibaraki prefecture, Japan*

\begin{tabular}{|c|c|c|c|c|}
\hline \multirow[b]{3}{*}{ Correlates } & \multicolumn{4}{|c|}{ Multiple regression† } \\
\hline & \multicolumn{2}{|c|}{ Male ( $n$ 262) } & \multicolumn{2}{|c|}{ Female $(n 171)$} \\
\hline & $\mathrm{B}$ & $P$ & B & $P$ \\
\hline Age & -0.007 & $<0.001$ & -0.001 & 0.63 \\
\hline $\mathrm{BMI}$ & -0.003 & 0.60 & -0.002 & 0.72 \\
\hline \multicolumn{5}{|l|}{ Medications } \\
\hline Anticonvulsants and/or major tranquillisers & $-0 \cdot 16$ & 0.001 & -0.03 & 0.57 \\
\hline Minor tranquillisers & -0.05 & 0.37 & -0.003 & 0.97 \\
\hline Other medications $\ddagger$ & $-0 \cdot 14$ & 0.002 & -0.03 & 0.55 \\
\hline $\mathrm{Hb}$ & 0.06 & $<0.001$ & 0.05 & $0 \cdot 16$ \\
\hline $\mathrm{Fe}$ & 0.001 & 0.02 & 0.001 & 0.44 \\
\hline C-reactive protein & -0.04 & 0.005 & -0.12 & $<0.001$ \\
\hline ZTT & -0.02 & $<0.001$ & -0.02 & 0.009 \\
\hline Individuals with cerebral palsy§ & $-0 \cdot 12$ & 0.02 & 0.01 & 0.80 \\
\hline Individuals with Down's syndrome§ & -0.27 & 0.001 & -0.06 & 0.62 \\
\hline Adjusted $R^{2}$ & \multicolumn{2}{|c|}{0.345} & \multicolumn{2}{|c|}{0.174} \\
\hline
\end{tabular}

ZTT, zinc sulfate turbidity test.

* Dataset for analysis excluded thirty-nine individuals with severe motor and intellectual disabilities from a total of 477 subjects. Additionally, data were missing for five subjects.

$\dagger$ In the multiple regression the dependent variable is serum albumin.

¥ Medications other than anticonvulsants and/or major tranquilisers, minor tranquilisers and Fe replacement (i.e. gastrointestinal drugs, drugs for the common cold, cardiovascular medication).

$\S$ Reference: individuals with intellectual disability. 
serum albumin level was found to be correlated with the use of medications and the presence of chronic and acute inflammation. Further research, using the present study as a baseline, is required to prospectively analyse the relationship between serum albumin levels and prognosis.

\section{Acknowledgements}

The present study was supported by a grant from Miyagi Gakuin Women's University. The authors declare that there are no conflicts of interest associated with this manuscript. H. O. and T. N. conceived of the study, and participated in its design, conducted the survey, analysed the data and wrote the manuscript.

\section{References}

1. Schalock RL, Stark JA, Snell ME, Coulter DL, Polloway EA, Luckasson R, Reiss S \& Spitalnik DM (1994) The changing conception of mental retardation: implications for the field. Ment Retard 32, 181-193.

2. Starker PM, Gump FE, Askanazi J, Elwyn DH \& Kinney JM (1982) Serum albumin levels as an index of nutritional support. Surgery 91, 194-199.

3. Salive ME, Cornoni-Huntley J, Phillips CL, Guralnik JM, Cohen HJ, Ostfeld AM \& Wallace RB (1992) Serum albumin in older persons: relationship with age and health status. J Clin Epidemiol 45, 213-221.
4. Cohen EP (1994) Predictors of mortality in patients undergoing hemodialysis. N Engl J Med 330, 573.

5. Corti MC, Guralnik JM, Salive ME \& Sorkin JD (1994) Serum albumin level and physical disability as predictors of mortality in older persons. JAMA 272, 1036-1042.

6. Rudman D \& Feller AG (1989) Protein-calorie undernutrition in the nursing home. J Am Geriatr Soc 37, 173-183.

7. Kergoat MJ, Leclerc BS, PetitClerc C \& Imbach A (1987) Discriminant biochemical markers for evaluating the nutritional status of elderly patients in long-term care. Am J Clin Nutr 46, $849-861$

8. Sugiyama M (2006) The revolution of nutritional care and management in the revised long-term care insurance (article in Japanese). J Natl Inst Public Health 55, 32-41.

9. Ohwada H, Nakayama T, Nara N, Tomono Y \& Yamanaka K (2006) An epidemiological study on anemia among institutionalized people with intellectual and/or motor disability with special reference to its frequency, severity and predictors. BMC Public Health 6, 85.

10. Matsuda R (1996-1998) Working Group on Nutritional Management Service in Older Persons Granted by the Ministry of Health, Labour and Welfare, Japan (in Japanese). Tokyo: Japanese Society on Nutrition Care and Management.

11. Iwaoka H, Yokoyama T, Masayasu S, Fuchi T, Nakayama T \& Tanaka H (1984) Characteristics of energy metabolism in males with mental retardation. J Nutr Sci Vitaminol 44, 151-164.

12. Gray DS (1989) Diagnosis and prevalence of obesity. Med Clin North Am 73, 1-13. 